\title{
'Second-Generation' Mephedrone Analogs, 4-MEC and 4-MePPP, Differentially Affect Monoamine Transporter Function
}

\author{
Kusumika Saha', John S Partilla², Kurt R Lehner², Amir Seddik ${ }^{3}$, Thomas Stockner', Marion Holy', \\ Walter Sandtner', Gerhard F Ecker ${ }^{3}$, Harald H Sitte ${ }^{1,4}$ and Michael H Baumann*,2 \\ 'Medical University of Vienna, Center for Physiology and Pharmacology, Institute of Pharmacology, Vienna, Austria; ${ }^{2}$ Designer Drug Research Unit \\ (DDRU), Intramural Research Program (IRP), NIDA, NIH, Baltimore, MD, USA; ${ }^{2}$ Department of Pharmaceutical Sciences, University of Vienna, \\ Vienna, Austria; ${ }^{4}$ Medical University of Vienna, Center for Addiction Research and Science, Vienna, Austria
}

\begin{abstract}
The nonmedical use of synthetic cathinones is increasing on a global scale. 4-Methyl-N-methylcathinone (mephedrone) is a popular synthetic cathinone that is now illegal in the United States and other countries. Since the legislative ban on mephedrone, a number of 'second-generation' analogs have appeared in the street drug marketplace, including 4-methyl-N-ethylcathinone (4-MEC) and 4'-methyl$\alpha$-pyrrolidinopropiophenone (4-MePPP). Here we characterized the interactions of 4-MEC and 4-MePPP with transporters for 5-HT (SERT) and dopamine (DAT) using molecular, cellular, and whole-animal methods. In vitro transporter assays revealed that 4-MEC displays unusual 'hybrid' activity as a SERT substrate (ie, 5-HT releaser) and DAT blocker, whereas 4-MePPP is a blocker at both transporters but more potent at DAT. In vivo microdialysis experiments in rat brain demonstrated that 4-MEC (I-3 mg/ $/ \mathrm{kg}$, i.v.) produced large increases in extracellular 5-HT, small increases in dopamine, and minimal motor stimulation. In contrast, 4-MePPP (I-3 mg/kg, i.v.) produced selective increases in dopamine and robust motor stimulation. Consistent with its activity as a SERT substrate, 4-MEC evoked inward current in SERT-expressing Xenopus oocytes, whereas 4-MePPP was inactive in this regard. To examine drug-transporter interactions at the molecular level, we modeled the fit of 4-MEC and 4-MePPP into the binding pockets for DAT and SERT. Subtle distinctions in ligand-transporter binding were found that account for the differential effects of 4-MEC and 4-MePPP at SERT. Collectively, our results provide key information about the pharmacology of newly emerging mephedrone analogs, and give clues to structural requirements that govern drug selectivity at DAT vs SERT.

Neuropsychopharmacology (20I5) 40, I32I-I33I; doi:I0.I038/npp.20I4.325; published online I4 January 20 I5
\end{abstract}

\section{INTRODUCTION}

In recent years, there has been an alarming increase in the nonmedical use of synthetic psychoactive compounds described as 'designer drugs' or 'legal highs' (Rosenbaum et al, 2012). These substances are synthesized by rogue chemists who hijack the medical and patent literature to identify structures that target specific neuronal receptors or transporters known to mediate psychoactive effects (Lewin et al, 2014). Synthetic cathinones are designer drugs given innocuous names like 'bath salts', 'plant food', or 'research chemicals' as a ploy to skirt the regulations governing the sale of psychoactive substances (Baumann et al, 2013a; De Felice et al, 2014). 4-Methyl- $N$-methylcathinone (mephedrone) and 3,4-methylenedioxypyrovalerone (MDPV) are examples of synthetic cathinones that produce stimulant-

*Correspondence: Dr MH Baumann, Designer Drug Research Unit, IRP, NIDA, NIH, DHHS, 333 Cassell Drive, Suite 4400, Baltimore, MD 21224, USA, Tel: +I 443740 2660, Fax: +I 443740 224I, E-mail: mbaumann@mail.nih.gov

Received 5 September 2014; revised 7 November 2014; accepted 9 November 2014; accepted article preview online 15 December 2015 like subjective effects at low doses, but dangerous side effects after high doses or chronic use (Dargan et al, 2011; Spiller et al, 2011). Adverse consequences include hypertension, tachycardia, anxiety, hallucinations, psychosis, and even death. Because of public health risks, legislative authorities have banned mephedrone, MDPV, and certain other synthetic cathinones in the United States (Drug Enforcement Administration (DEA), Department of Justice, 2013), and similar legislation has been enacted in European countries. In response to legislative bans, enterprising chemists have synthesized a number of 'second-generation' replacement analogs as a means to evade regulatory control, and this trend is expected to continue (Leffler et al, 2014; Marinetti and Antonides, 2013).

Like other stimulant drugs, synthetic cathinones exert their pharmacological effects by disrupting the function of solute carrier SLC6 transporter proteins (ie, monoamine transporters) expressed on nerve cells in the brain and periphery (Baumann et al, 2013a; Hadlock et al, 2011; Lopez-Arnau et al, 2012). Monoamine transporters normally mediate the sodium-dependent reuptake of monoamine neurotransmitters, and there are specific transporter proteins for norepinephrine (NET), dopamine (DAT), 
and 5-HT (SERT) (Kristensen et al, 2011). Drugs that interact with transporters can be categorized as either amphetamine-like substrates or cocaine-like blockers (Rothman and Baumann, 2003; Sitte and Freissmuth, 2010). Both types of drugs increase extracellular concentrations of monoamines in nervous tissue, but substrates induce transporter-mediated sodium currents (ie, depolarization) and evoke transmitter efflux (ie, release), whereas blockers do not. Importantly, determining the precise molecular mechanism of action for transporter drugs is critical to predict their putative toxic potential (Baumann et al, 2014; Steinkellner et al, 2011). Previous studies have shown that mephedrone targets monoamine transporters as a nonselective substrate, thereby evoking the release of norepinephrine, dopamine, and 5-HT (Baumann et al, 2012; Cameron et al, 2013; Eshleman et al, 2013; Simmler et al, 2013). In contrast, MDPV is a potent blocker at NET and DAT with little influence on SERT. Systemic administration of mephedrone or MDPV to rats increases extracellular concentrations of dopamine in mesolimbic reward pathways, indicating the potential for addiction (Baumann et al, 2012, 2013b; Kehr et al, 2011; Wright et al, 2012). Accordingly, both drugs are readily selfadministered and facilitate intracranial self-stimulation in rat models (Aarde et al, 2013a; Bonano et al, 2014; Hadlock et al, 2011; Watterson et al, 2014).

As noted above, a number of second-generation analogs of mephedrone and MDPV have recently appeared in the recreational drug marketplace (Leffler et al, 2014; Marinetti and Antonides, 2013). We and others have shown that newly emerging analogs of MDPV, like $\alpha$-pyrrolidinovalerophenone $(\alpha-P V P)$, are potent blockers at DAT and NET (Kolanos et al, 2013; Marusich et al, 2014). However, little information is available regarding the molecular mechanisms and pharmacological effects of mephedrone analogs (ie, 4-methyl ring-substituted compounds) such as 4-methyl- $N$-ethylcathinone (4-MEC) and $4^{\prime}$-methyl- $\alpha$ pyrrolidinopropiophenone (4-MePPP). Figure 1 shows the chemical structures of 4-MEC and 4-MePPP as compared with mephedrone; both drugs maintain the 4-methyl ring-substitution of mephedrone, but 4-MEC has an $\mathrm{N}$-ethyl group whereas 4 -MePPP has an $\mathrm{N}$-butyl group that is cyclized to form a pyrrolidine ring. 4-MEC has been identified in products purchased from internet vendors (eg, NRG-2) (Ayres and Bond, 2012), and the drug is associated with adverse medical consequences (Gil et al, 2013; Rojek
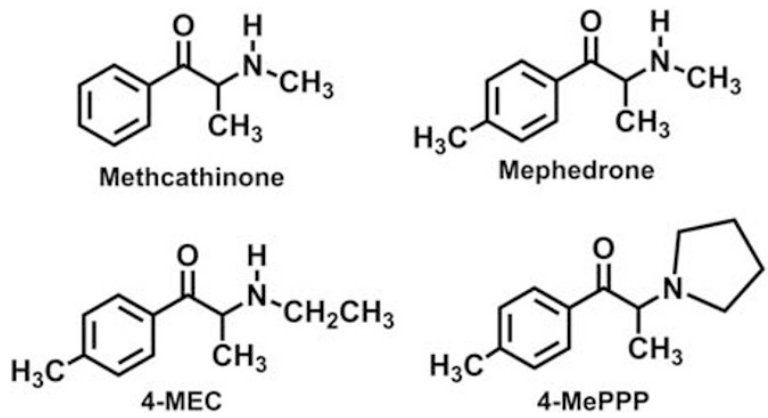

Figure I Chemical structure of 4-methyl-N-ethylcathinone (4-MEC) and $4^{\prime}$-methyl- $\alpha$-pyrrolidinopropiophenone (4-MePPP), as compared with $\mathrm{N}$-methylcathinone (methcathinone) and 4-methyl- $\mathrm{N}$-methylcathinone (mephedrone). et al, 2014). 4-MePPP was available as a recreational stimulant in the late 1990s and was scheduled by the German Controlled Substance Act that prohibited its sale and use. Initial studies with 4-MePPP involved the characterization of its metabolism and development of forensic assays to detect the drug in biological matrices (Springer et al, 2003; Springer et al, 2002). 4-MePPP has reappeared recently in products containing mixtures of cathinone-related compounds (eg, NRG-3) (Brandt et al, 2011). In the present study, we employed molecular, cellular, and whole-animal methods to examine the interactions of 4-MEC and 4-MePPP with monoamine transporters. In vitro transporter assays were carried out in rat brain synaptosomes and in cells expressing human transporters. Effects of drugs on in vivo neurochemistry were monitored using microdialysis in rat nucleus accumbens. Finally, we analyzed transportermediated currents evoked by these drugs in Xenopus oocytes expressing SERT. Our results reveal diverse profiles of transporter activity for 4-MEC and 4-MePPP when compared with mephedrone.

\section{MATERIALS AND METHODS}

\section{Drugs and Reagents}

For uptake and release assays in synaptosomes, $\left[{ }^{3} \mathrm{H}\right]$ dopamine, $\left[{ }^{3} \mathrm{H}\right] 5-\mathrm{HT}$, and $\left[{ }^{3} \mathrm{H}\right] 1$-methyl-4-phenylpyridinium $\left(\left[{ }^{3} \mathrm{H}\right] \mathrm{MPP}+\right)$ were purchased from Dupont New England Nuclear (Boston, MA). All reagents, buffer salts, and chemicals were obtained from Sigma Chemical (St Louis, MO) unless otherwise noted. Reagents used in the experiments for uptake and efflux assays in cells were purchased and used according to previous work (Hofmaier et al, 2014). Plasmids encoding human SERT were a generous gift of Dr Randy D Blakely.

\section{Animals and Housing}

Male Sprague-Dawley rats (Charles River, Wilmington, MA) weighing $250-350 \mathrm{~g}$ were housed in standard conditions (lights on 0700-1900 h) with food and water freely available. Rats were maintained in facilities fully accredited by the Association for Assessment and Accreditation of Laboratory Animal Care, and experiments were performed in accordance with the Institutional Care and Use Committee of the NIDA IRP. Xenopus laevis frogs (Nasco, Fort Atkinson, WI) were kept in aquaria on a strict $12 \mathrm{~h}$ light/dark schedule with food available once weekly.

\section{Uptake and Release Assay in Rat Brain Synaptosomes}

Uptake and release assays were carried out in rat brain synaptosomes as previously described (Baumann et al, 2013 b). Synaptosomes were prepared from rat striatum for DAT assays, whereas synaptosomes were prepared from whole brain minus striatum and cerebellum for SERT assays. For uptake inhibition assays, $5 \mathrm{nM}\left[{ }^{3} \mathrm{H}\right]$ dopamine and $\left[{ }^{3} \mathrm{H}\right] 5$ HT were used to assess transport activity at DAT and SERT, respectively. The selectivity of uptake assays was optimized for a single transporter by including unlabeled blockers to prevent uptake of $\left[{ }^{3} \mathrm{H}\right]$ transmitter by competing transporters. Uptake inhibition assays were initiated by adding 
$100 \mu \mathrm{l}$ of tissue suspension to $900 \mu \mathrm{l}$ Krebs-phosphate buffer containing test drug and $\left[{ }^{3} \mathrm{H}\right]$ transmitter. Uptake inhibition assays were terminated by rapid vacuum filtration through Whatman GF/B filters, and retained radioactivity was quantified by liquid scintillation counting. For release assays, $9 \mathrm{nM}\left[{ }^{3} \mathrm{H}\right] \mathrm{MPP}+$ was used as the radiolabeled substrate for DAT, whereas $5 \mathrm{nM}\left[{ }^{3} \mathrm{H}\right] 5-\mathrm{HT}$ was used as the radiolabeled substrate for SERT. All buffers used in the release assays contained $1 \mu \mathrm{M}$ reserpine to block vesicular uptake of substrates. The selectivity of release assays was optimized for a single transporter by including unlabeled blockers to prevent the uptake of $\left[{ }^{3} \mathrm{H}\right] \mathrm{MPP}+$ or $\left[{ }^{3} \mathrm{H}\right] 5-\mathrm{HT}$ by competing transporters. Synaptosomes were preloaded with radiolabeled substrate in Krebs-phosphate buffer for $1 \mathrm{~h}$ (steady state). Release assays were initiated by adding $850 \mu \mathrm{l}$ of preloaded synaptosomes to $150 \mu \mathrm{l}$ of test drug. Release was terminated by vacuum filtration and retained radioactivity was quantified as described for uptake inhibition.

\section{In Vivo Microdialysis in Rat Nucleus Accumbens}

Microdialysis procedures were carried out as previously described (Baumann et al, 2012). Male rats were surgically prepared with jugular catheters and intracerebral guide cannulae aimed at the nucleus accumbens $(\mathrm{AP}+1.6 \mathrm{~mm}$, $\mathrm{ML}-1.7 \mathrm{~mm}$ relative to bregma; $-6.2 \mathrm{~mm}$ relative to dura). After a 7-10-day recovery period, catheters were attached to extension tubes and $0.5 \times 2 \mathrm{~mm}$ microdialysis probes (CMA/12, Harvard Apparatus, Holliston, MA) were inserted into guide cannulae. Ringer's solution was perfused through the probe at $0.5 \mu \mathrm{l} / \mathrm{min}$ and dialysate samples were collected at $20 \mathrm{~min}$ intervals. Drug treatments were given after three stable baseline samples were obtained. Rats received two i.v. drug injections, $1 \mathrm{mg} / \mathrm{kg}$ at time 0 followed by $3 \mathrm{mg} / \mathrm{kg} 60 \mathrm{~min}$ later. Control rats received two i.v. saline injections on the same schedule. Concentrations of 5-HT and dopamine were quantified using high-pressure liquid chromatography coupled to electrochemical detection (HPLC-ECD). Dialysate samples were injected onto a microbore HPLC column coupled to an EC detector with a glassy carbon electrode set at $+650 \mathrm{mV}$ relative to $\mathrm{Ag} / \mathrm{AgCl}$ reference. Mobile phase was pumped at $60 \mu \mathrm{l} / \mathrm{min}$. Chromatographic data were exported to an Empower software system (Waters, Milford, MA) for peak identification, integration, and analysis.

\section{Uptake and Release Assay in HEK293 Cells}

The uptake and release assays in HEK293 cells were carried out as previously described (Hofmaier et al, 2014). For uptake assays, cells were washed twice with Krebs HEPES buffer. Test drugs were added to cells for $5 \mathrm{~min}$ allowing equilibration with transporters. Subsequently, $\left[{ }^{3} \mathrm{H}\right] 5-\mathrm{HT}$ and $\left[{ }^{3} \mathrm{H}\right]$ dopamine were added, and the reaction was stopped after allowing uptake for $1 \mathrm{~min}$. The uptake was terminated by washing with $500 \mu \mathrm{l}$ of ice-cold Krebs HEPES buffer, cells were lysed with $500 \mu$ of $1 \%$ sodium dodecyl sulfate, and tritium was counted on a Packard 2300 TR TriCarb Liquid Scintillation Analyzer. For release studies, HEK293 cells expressing hSERT or hDAT were grown overnight on round glass coverslips (5-mm diameter, 40000 cells per coverslip) placed in a 96-well plate and preloaded with $0.4 \mu \mathrm{M}\left[{ }^{3} \mathrm{H}\right] 5 \mathrm{HT}$ or $0.03 \mu \mathrm{M}\left[{ }^{3} \mathrm{H}\right] \mathrm{MPP}+$ for $20 \mathrm{~min}$ at $37^{\circ} \mathrm{C}$ in a final volume of $0.1 \mathrm{ml} /$ well. Coverslips were transferred to small chambers $(0.2 \mathrm{ml})$ and superfused with Krebs HEPES buffer $\left(25^{\circ} \mathrm{C}, 0.7 \mathrm{ml} / \mathrm{min}\right)$. The $40 \mathrm{~min}$ baseline for efflux of radioactivity was followed by addition of test drugs and collection of fractions every $2 \mathrm{~min}$. The experiment was terminated by lysis of the cells with $1 \%$ sodium dodecyl sulfate and counted.

\section{Electrophysiological Recordings in X. laevis Oocytes}

Electrophysiology recordings were performed as recently described (Baumann et al, 2014). Briefly, the plasmid containing hSERT was linearized and in vitro transcription was carried out using a T7 RNA polymerase Kit mMessage mMachine (Ambion, Life Technologies, Grand Island, NY). Stage V-VI oocytes were obtained from X. laevis and transferred to calcium-free Ringer's solution. The oocytes were separated into smaller lobes containing 3 to 5 oocytes and defolliculated by enzymatic digestion with collagenase from Clostridium histolyticum $(1 \mathrm{mg} / \mathrm{ml})$ for $60 \mathrm{~min}$. Oocytes were selected and transferred to Ringer's solution. Oocytes were kept at $18{ }^{\circ} \mathrm{C}$ in Ringer's solution containing $2.5 \mathrm{mM}$ sodium pyruvate, $100 \mu \mathrm{g} / \mathrm{ml}$ penicillin, and $100 \mu \mathrm{g} /$ $\mathrm{ml}$ streptomycin. In each oocyte, $10 \mathrm{ng}$ of the prepared hSERT RNA was microinjected. The oocytes were maintained for 7-10 days for functional studies, and solution was changed twice daily. A CA-1B high-performance oocyte clamp was employed for the measurements. The recorded signal was digitized with Digidata 13222A (Axon Instruments, Molecular Devices, Sunnyvale, CA). An Intel PC running pCLAMP 9.2 (Axon Instruments) was used for acquisition. Borosilicate glass capillaries were pulled to a final resistance of $0.4-1.2 \mathrm{M} \Omega$ and filled with $3 \mathrm{M} \mathrm{KCl}$. Oocytes were impaled and the membrane potential was clamped to a holding potential of $-60 \mathrm{mV}$. For continuous superfusion with $\mathrm{ND} 100$ solution $(100 \mathrm{mM} \mathrm{NaCl}, 2 \mathrm{mM} \mathrm{KCl}$, $1 \mathrm{mM} \mathrm{CaCl}_{2}, 1 \mathrm{mM} \mathrm{MgCl}_{2}, 10 \mathrm{mM}$ HEPES, pH adjusted to 7.4 with $\mathrm{NaOH}$ ), a gravity-driven superfusion system was used. Recordings were started after a stable current baseline was established. The current was sampled with $100 \mathrm{~Hz}$ and low pass filtered with $20 \mathrm{~Hz}$.

\section{Ligand and Protein Model Preparation}

The ligand structures were built as $(S)$-enantiomers in protonated form using the software MOE (Molecular Operating Environment (MOE), Montreal, QC, Canada). The recently crystallized Drosophila DAT, in the outward facing conformation in complex with nortriptyline $\left(\mathrm{dDAT}_{\text {cryst }}\right)$, was used as a template for transporter modeling (Penmatsa et al, 2013). dDAT displays close to $70 \%$ sequence homology with hSERT, hDAT, and hNET in the substratebinding pocket. Sequence alignment was performed using ClustalX (Thompson et al, 2002). Nonstructural waters were removed from the $\mathrm{dDAT}_{\text {cryst }}$ structure and 250 homology models of each of the human transporters in complex with nortriptyline were created using Modeller 9.11 (Sali et al, 1995). Nortriptyline has dissociation constants $\left(K_{\mathrm{D}}\right)$ of $18 \mathrm{nM}$ at hSERT, $1140 \mathrm{nM}$ at hDAT, and $4.4 \mathrm{nM}$ at hNET (Tatsumi et al, 1997). The models with the highest 'Discrete Optimization of Protein Energy' (DOPE) score showed no 
disallowed dihedrals near the central binding site and were protonated at $\mathrm{pH} 7$ using the Protonate3D tool in MOE. Nortriptyline and residues within a radius of $5 \AA$ were energy minimized using a distance-dependent dielectric constant of 2 (Hou et al, 2011) to 80 in the OPLS-AA force field (Jorgensen et al, 1996).

\section{Docking of 4-MEC and 4-MePPP}

In order to determine the influence of the SERT Thr439 conformation on ligand placement, the side chain was rotated by $180^{\circ}$ along its $\mathrm{C}_{\alpha}-\mathrm{C}_{\beta}$ bond. The binding site topology was optimized by energy minimization of nortriptyline (or Thr439 in SERT) as noted above for dDAT (Hou et al, 2011; Jorgensen et al, 1996). The transporterligand complexes were loaded into the docking software GOLD 5.2 (Jones et al, 1997) that uses a genetic algorithm to obtain poses nondeterministically. Waters were removed and the binding site was defined as the center of mass of the inhibitor. The cathinone substructure was used for setting restraints, whereby the cationic nitrogen was forced to be within $2-4 \AA$ to the Tyr95/Phe76 (SERT/DAT) backbone carbonyl oxygen. This is in analogy to the positive partial charge density of antidepressant ligands in $\mathrm{dDAT}_{\text {cryst }}$ and in the humanized leucine transporter structures (Wang et al, 2013). Binding modes were generated 50 times per ligand using GoldScore with maximum search efficiency, and the poses retrieved were clustered based on their placement into specific subpockets.

\section{Data Analysis and Statistics}

For uptake and release assays, the data from three experiments were fit to a dose-response curve equation, and $\mathrm{IC}_{50}$ or $\mathrm{EC}_{50}$ values were calculated using GraphPad Prism. For microdialysis experiments, the first three samples collected were considered baseline samples and all subsequent monoamine measures were expressed as a percentage of the mean of this baseline. Effects of drugs on dialysate 5-HT and dopamine were evaluated using two-way ANOVA (treatment $\times$ time) followed by Bonferroni post hoc tests at specific time points after drug injection. For transporter-mediated currents, the comparison of the maximum currents across drugs was analyzed by one-way ANOVA with Tukey's post hoc test. $P<0.05$ was chosen as the minimum criterion for statistical significance.

\section{RESULTS}

\section{Effects of 4-MEC and 4-MePPP on DAT and SERT in Synaptosomes}

Figure 2 depicts the effects of mephedrone, 4-MEC, and 4-MePPP in transporter assays carried out in rat brain synaptosomes. The ability of test drugs to inhibit uptake of $\left[{ }^{3} \mathrm{H}\right] 5-\mathrm{HT}$ and $\left[{ }^{3} \mathrm{H}\right]$ dopamine is shown in Figure $2 \mathrm{a}$ and $\mathrm{b}$, respectively. Mephedrone and 4-MEC displayed nearly equal potency at inhibiting uptake at SERT $\left(\mathrm{IC}_{50}=\right.$ $\sim 500 \mathrm{nM})$ and at DAT $\left(\mathrm{IC}_{50}=\sim 800 \mathrm{nM}\right)$. In contrast, 4-MePPP was much more potent as an inhibitor at DAT when compared with SERT, with an $\mathrm{IC}_{50}=215 \pm 13 \mathrm{nM}$ at DAT $v s \mathrm{IC}_{50}=>10000 \mathrm{nM}$ at SERT. Thus, mephedrone and
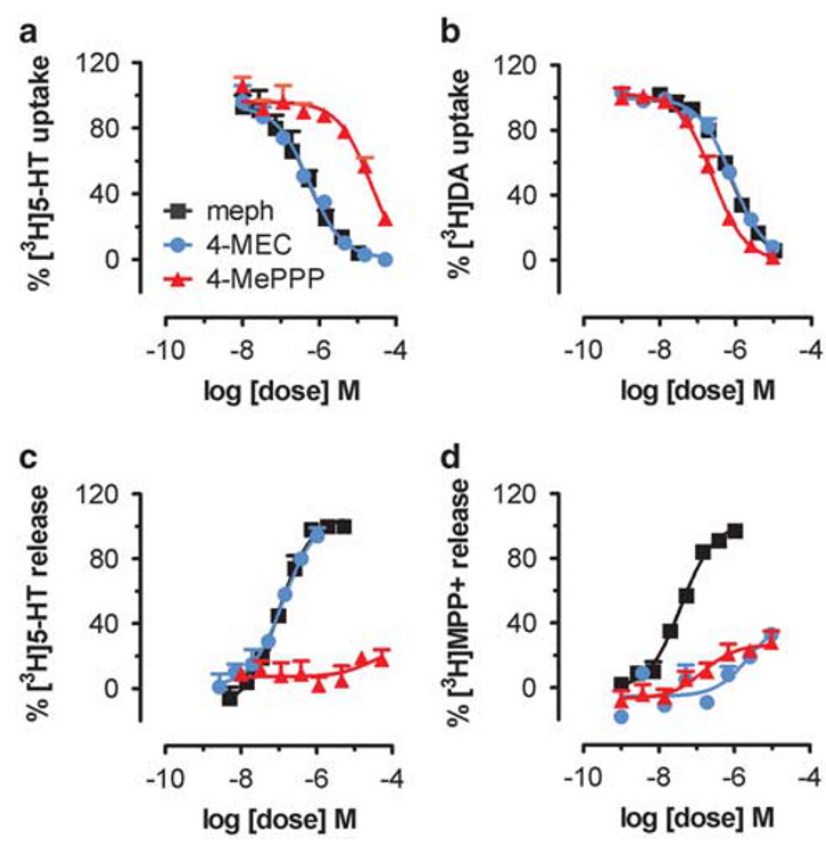

Figure 2 Effects of 4-MEC and 4-MePPP on transporter-mediated uptake and release in rat brain synaptosomes. Inhibition of $\left.{ }^{3} \mathrm{H}\right] 5-\mathrm{HT}$ uptake (a) and $\left[{ }^{3} \mathrm{H}\right] \mathrm{DA}$ uptake (b) by 4-MEC, 4-MePPP, and mephedrone. Release of preloaded $\left.{ }^{3} \mathrm{H}\right] 5-\mathrm{HT}$ from SERT (c) and $\left.{ }^{3} \mathrm{H}\right] \mathrm{MPP}+$ from DAT (d) evoked by 4-MEC, 4-MePPP, and mephedrone. Data are mean \pm SD for $N=3$ separate experiments performed in triplicate.

4-MEC are nonselective uptake blockers, whereas 4-MePPP is 40-fold selective for DAT over SERT. As discussed in previous publications (Baumann et al, 2012, 2013a), the effects of drugs in uptake inhibition assays cannot reveal whether drugs are acting as transporter blockers or substrates, and hence we next tested the effects of drugs in the synaptosome release assay. The ability of test drugs to evoke release of preloaded $\left[{ }^{3} \mathrm{H}\right] 5-\mathrm{HT}$ and $\left[{ }^{3} \mathrm{H}\right] \mathrm{MPP}+$ is shown in Figure $2 \mathrm{c}$ and $\mathrm{d}$, respectively. Mephedrone and 4-MEC displayed similar potency in their ability to evoke $\left[{ }^{3} \mathrm{H}\right] 5-\mathrm{HT}$ release from SERT $\left(\mathrm{EC}_{50}=\sim 100 \mathrm{nM}\right)$, whereas 4 -MePPP was inactive as a releaser at SERT. Interestingly, mephedrone was a fully efficacious releaser of $\left[{ }^{3} \mathrm{H}\right] \mathrm{MPP}+$ at DAT $\left(\mathrm{EC}_{50}=39 \pm 3 \mathrm{nM}\right)$, but $4-\mathrm{MEC}$ and 4 -MePPP were both inactive in this regard.

Effects of 4-MEC and 4-MePPP on Neurochemistry and Behavior in vivo

Figure 3 depicts the effects of i.v. administration of 4-MEC and 4-MePPP on neurochemistry and locomotor activity in rats undergoing microdialysis in the nucleus accumbens. Figure 3a demonstrates a main effect of drug treatment on extracellular 5-HT $\left(\mathrm{F}_{2,16}=34.38, p<0.0001\right)$. 4-MEC produced significant dose-related increases in extracellular 5 -HT, with $1 \mathrm{mg} / \mathrm{kg}$ producing a 3.2 -fold elevation above baseline, and $3 \mathrm{mg} / \mathrm{kg}$ producing a 6.9 -fold elevation. In marked contrast, 4-MePPP had no significant effect on extracellular 5-HT at either dose tested. Figure $3 \mathrm{~b}$ shows a main effect of drug treatment on extracellular dopamine $\left(\mathrm{F}_{2,16}=27.26, p<0.0001\right)$, and the effects of 4 -MEC and 4-MePPP on dopamine were opposite to the changes in 5-HT. More specifically, 4-MePPP produced dose-related 

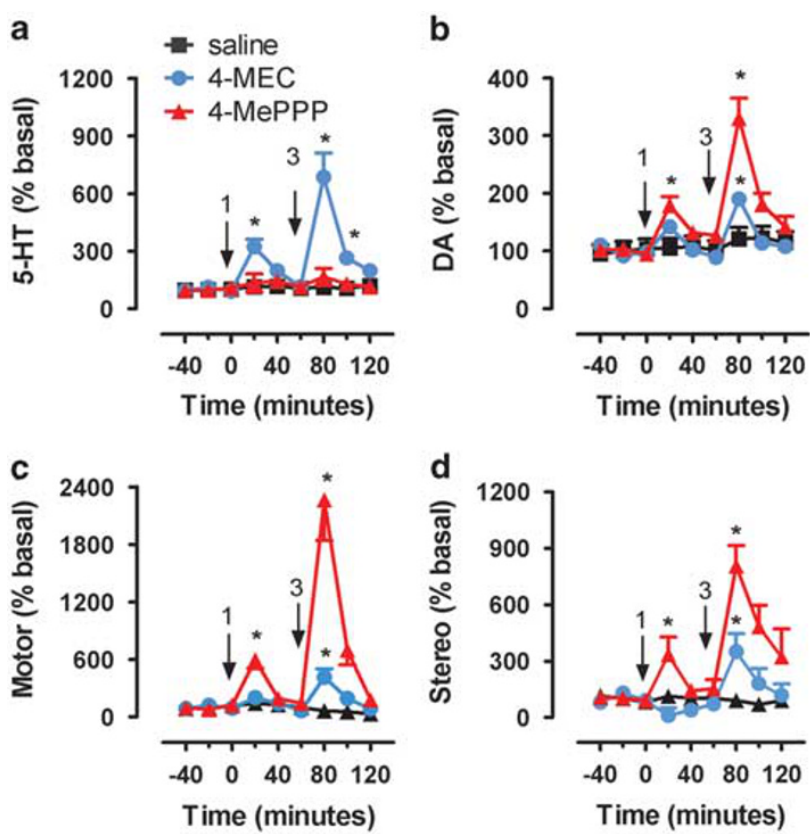

Figure 3 Effects of i.v. administration of saline, 4-MEC, and 4-MePPP on neurochemistry and behavior in rats undergoing microdialysis in nucleus accumbens. Effects of saline, 4-MEC, and 4-MePPP on dialysate 5-HT (a) and dialysate dopamine (DA) (b). Effects of saline, 4-MEC, and 4-MePPP on forward locomotion (Motor) (c) and stereotypic movements (Stereo) (d). Data are mean \pm SEM expressed as $\%$ baseline for $N=6-7$ rats/group. Arrows indicate time of injections and numbers indicate i.v. mg/kg doses. *P $<0.05$ compared with saline-injected control at specific time points.

increases in extracellular dopamine, with $1 \mathrm{mg} / \mathrm{kg}$ producing a 1.8-fold elevation above baseline and $3 \mathrm{mg} / \mathrm{kg}$ producing a 3.3-fold elevation. 4-MEC, on the other hand, produced no effect on dopamine at $1 \mathrm{mg} / \mathrm{kg}$, but a 1.9 -fold increase after the $3 \mathrm{mg} / \mathrm{kg}$ dose. Figure $3 \mathrm{c}$ and d demonstrate that drug treatment had main effects on forward locomotion $\left(\mathrm{F}_{2,16}=40.66, p<0.0001\right)$ and stereotypy $\left(\mathrm{F}_{2,16}=20.98, p<0.0001\right)$. 4-MEC produced small increases in both parameters, but only after the high dose; 4-MePPP produced striking dose-related effects that were much greater than the effects of 4-MEC. Importantly, the motor effects of both drugs were short-lived and quickly returned to baseline values by $60 \mathrm{~min}$ after injection.

\section{Effects of 4-MEC and 4-MePPP on Human Transporters Expressed in Cells}

Based on the results from rat experiments, we wished to explore the molecular mechanism of action for 4-MEC and 4-MePPP in greater detail, and hence the effects of these drugs were examined in HEK293 cells stably expressing human transporters. Figure $4 \mathrm{a}$ and $\mathrm{b}$ show the effects of test drugs on uptake inhibition in cells expressing human SERT (hSERT) or human DAT (hDAT), respectively. In agreement with findings from synaptosomes, 4-MEC showed nonselective inhibition of uptake, with $\mathrm{IC}_{50}$ values of $10.9 \pm 2.2 \mu \mathrm{M}$ at hSERT and $3.9 \pm 0.4 \mu \mathrm{M}$ at hDAT. In contrast, 4-MePPP displayed much higher potency at inhibiting uptake at hDAT $\left(\mathrm{IC}_{50}=1.08 \pm 0.1 \mu \mathrm{M}\right)$ when compared with hSERT $\left(\mathrm{IC}_{50}=126 \pm 36 \mu \mathrm{M}\right)$. Next, we compared the effects of 4-MEC and 4-MePPP on transporter-mediated efflux using superfusion methods. In these experiments, the time-dependent efflux of $\left[{ }^{3} \mathrm{H}\right] 5$ HT through hSERT and $\left[{ }^{3} \mathrm{H}\right] \mathrm{MPP}+$ through hDAT was assessed in the presence or absence of monensin $(10 \mu \mathrm{M})$, an ionophore that dissipates the normal $\mathrm{Na}+$ gradient across cell membranes and selectively enhances the efflux caused by transporter substrates (Baumann et al, 2013b; Scholze et al, 2000). Thus, monensin can be used to discriminate the effects of transporter substrates $v s$ blockers. Figure $4 \mathrm{c}$ shows that 4 -MEC $(10 \mu \mathrm{M})$ induced efflux of $\left[{ }^{3} \mathrm{H}\right] 5-\mathrm{HT}$ but 4 -MePPP did not. Importantly, the efflux of $\left[{ }^{3} \mathrm{H}\right] 5-\mathrm{HT}$ produced by 4 -MEC was dramatically enhanced in the presence of monensin, confirming that $4-\mathrm{MEC}$ is a substrate at hSERT. Figure $4 \mathrm{~d}$ demonstrates that 4-MEC and 4-MePPP both induced modest efflux of $\left[{ }^{3} \mathrm{H}\right] \mathrm{MPP}+$ at hDAT, but in neither case was this response altered by monensin.

\section{Effects of 4-MEC and 4-MePPP on SERT-Mediated Currents}

As a final test to confirm that 4-MEC and 4-MePPP display differential effects at SERT, we examined transportermediated currents in oocytes expressing hSERT (Baumann et al, 2014). For these experiments, the effects of drugs were only evaluated in SERT-expressing cells as neither drug elicited substrate activity at DAT. Figure 5a and b depict the effects of 4-MEC and 4-MePPP on SERT-mediated currents, respectively. 4-MEC evoked robust dose-related inward currents that followed a bell-shaped dose response. The greatest magnitude of current produced by 4-MEC $(30 \mu \mathrm{M})$ was nearly equivalent to that produced by $10 \mu \mathrm{M}$ 5-HT. Consistent with the profile of a transporter blocker, 4-MePPP did not elicit any transporter mediated-current at doses up to $100 \mu \mathrm{M}$. Figure $5 \mathrm{c}$ shows the current-inducing effects of 4-MEC and 4-MePPP when normalized to the effects of $10 \mu \mathrm{M} 5$-HT. This figure highlights the bell-shaped dose response for 4-MEC and the lack of effect for 4-MePPP.

\section{Computational Docking with 4-MEC and 4-MePPP}

The differential effects of 4-MEC and 4-MePPP at SERT prompted us to employ a molecular docking approach to explore the structural peculiarities between SERT and DAT, and possible differences in the binding modes of the two compounds. The binding modes of the two cathinones in the hSERT and hDAT homology models were analogous to the LeuBAT inhibitor binding mode (Wang et al, 2013), whereby the aromatic rings are placed in the previously reported subpocket B (Andersen et al, 2010; Seddik et al, 2013). 4-MEC and 4-MePPP only differ in their $\mathrm{N}$-substitution, with 4 -MePPP having a sterically more demanding substituent (pyrrolidine ring $v s$ ethyl chain). Remarkably, this difference causes a $>100$-fold decrease in the affinity of 4-MePPP for SERT vs DAT. It seems unlikely that this is solely due to differences in the interaction of the cathinone nitrogen with distinct amino acids, as the only difference in the binding site is F76/Y95 (Table 1). Figure 6 depicts docking poses of 4-MEC and 4-MePPP in hDAT (Figure 6a) and hSERT (Figure $6 \mathrm{~b}$ and c). Although both compounds show analogous poses in hDAT, which is 

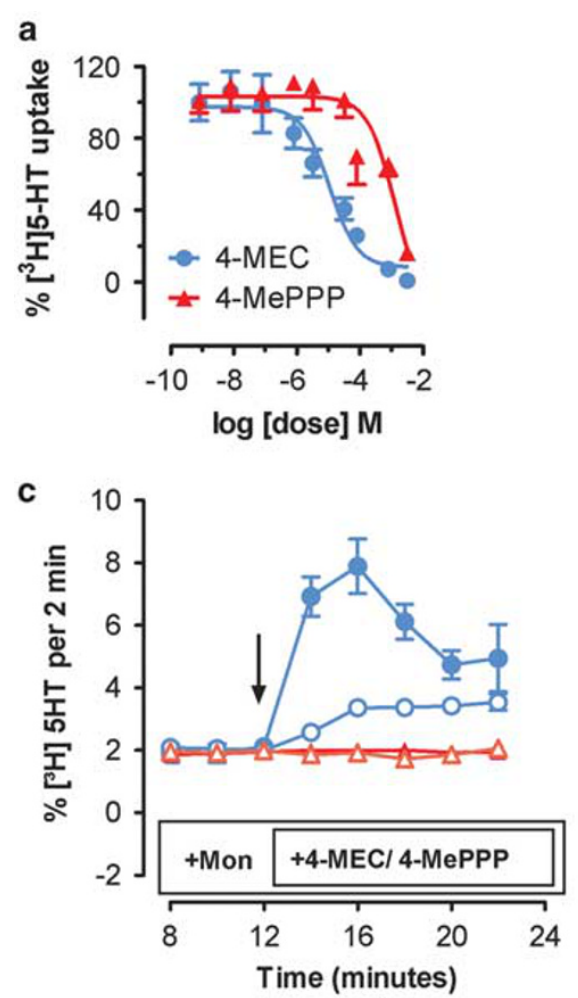
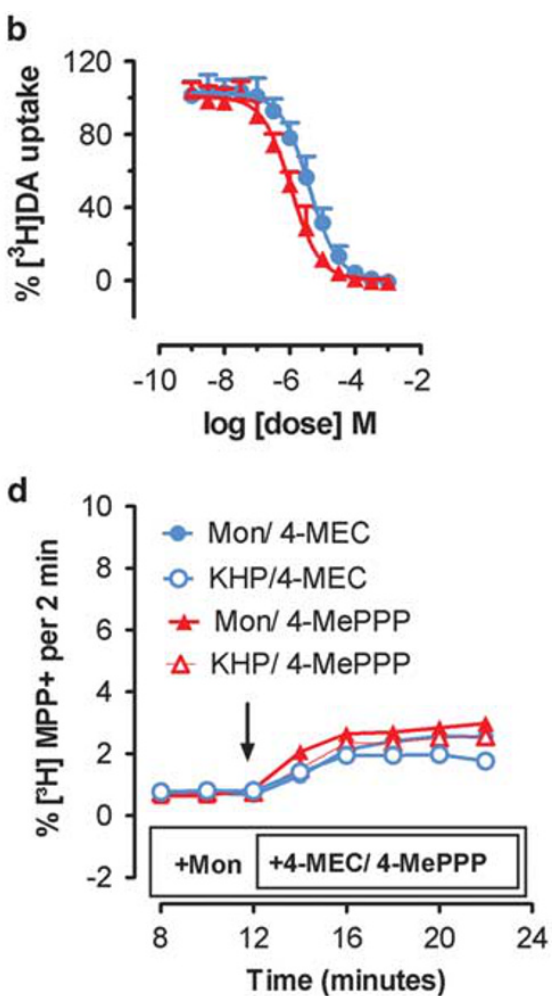

Figure 4 Inhibition of uptake and stimulation of efflux produced by 4-MEC and 4-MePPP in HEK293 cells stably expressing hSERT and hDAT. Inhibition of $\left[{ }^{3} \mathrm{H}\right] 5-\mathrm{HT}$ uptake by hSERT (a) and $\left.{ }^{3} \mathrm{H}\right] \mathrm{DA}$ uptake by hDAT (b) in cells. Efflux of $\left[{ }^{3} \mathrm{H}\right] 5-\mathrm{HT}$ (c) and $\left[^{3} \mathrm{H}\right] \mathrm{MPP}+$ (d) via hSERT and hDAT, respectively. Effects of $10 \mu \mathrm{M}$ 4-MEC and $10 \mu \mathrm{M}$ 4-MePPP on efflux were carried out in the presence of Krebs HEPES buffer (KHP) or $10 \mu \mathrm{M}$ monensin. Arrows show the administration of 4-MEC/4-MePPP. Data are mean \pm SD for $n=3$ separate experiments.

supported by their similar effects at inhibiting $\left[{ }^{3} \mathrm{H}\right]$ dopamine uptake, the placement in hSERT is less consistent. Importantly, this inconsistency only affects $4-\mathrm{MePPP}$, which shows two clusters, with the aromatic moiety being placed either deeper in subpocket B or in subpocket C. The latter configuration seems unlikely, as no transporter inhibitor was found to occupy this site in LeuBATs. Thus, the ambiguous positioning of 4-MePPP in hSERT might be because of its larger $\mathrm{N}$-pyrrolidino substituent that forces a slight shift deeper into subpocket B when compared with the case for 4-MEC. In the case of subpocket B of hDAT, there is sufficient space to accommodate 4-MePPP because of the smaller side chains present (ie, Ala423, Val152, and Gly153); subpocket B in hSERT is formed by bulkier aminoacid side chains (Thr439, Ile172, and Ala173). In particular, Thr439 might be responsible for steric repulsion of 4MePPP in hSERT, rendering the complex less stable. Thus, two different side chain conformations of Thr439 were probed and similar docking patterns were found (Figure $6 \mathrm{~b}$ and c), whereby either the polar hydroxyl group or a proximal methyl group repels the positioning of 4-MePPP. In addition, reducing the flexibility of Thr439 upon binding of 4-MePPP also leads to an entropically unfavorable contribution to the binding free energy.

\section{DISCUSSION}

A major goal of our study was to determine the mechanism of action and pharmacological effects of the mephedrone analogs, 4-MEC and 4-MePPP. In previous publications, we and others have shown that mephedrone is a nonselective substrate for monoamine transporters, thereby causing the release of 5-HT, dopamine, and norepinephrine (Baumann et al, 2012; Eshleman et al, 2013; Simmler et al, 2013). Once legislation was enacted to render mephedrone illegal, 4MEC and 4-MePPP began appearing in the recreational drug marketplace (Ayres and Bond, 2012; Brandt et al, 2011; Leffler et al, 2014), and 4-MEC has been associated with adverse medical consequences leading to death (Gil et al, 2013; Rojek et al, 2014). The present in vitro findings from rat brain synaptosomes show that 4-MEC displays unique activity as a SERT substrate/DAT blocker, whereas 4-MePPP is a DAT blocker with little activity at SERT. Consistent with synaptosome data, i.v. administration of 4-MEC induces predominant elevations in brain extracellular 5-HT, whereas 4-MePPP induces selective elevations in dopamine. Importantly, the effects of 4-MEC and 4-MePPP in cells expressing human transporters agree with the findings in rat brain synaptosomes. Using molecular modeling techniques, we provide evidence that differences in amino-acid composition of the ligand-binding pockets of hDAT and hSERT can explain the ability of 4-MePPP to selectively interact with hDAT. Overall, our findings reinforce the concept that subtle changes in cathinone structure can dramatically alter drug pharmacology.

One of the most interesting findings from our experiments in synaptosomes is the unusual transporter activity of 4-MEC as compared with mephedrone. 4-MEC represents a rare example of a compound that exhibits substrate 
a
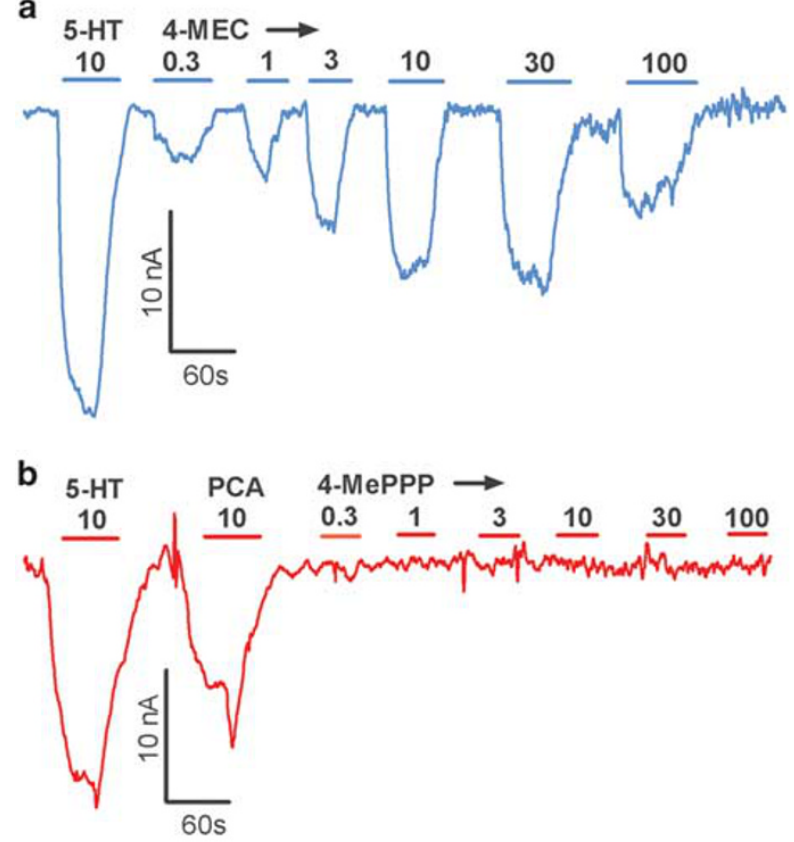

c

$\log$ [dose] M

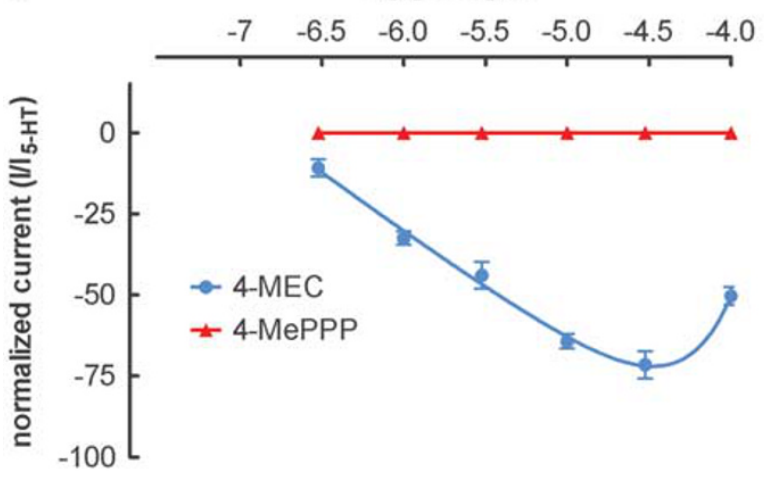

Figure 5 Dose-response effects of 4-MEC and 4-MePPP on SERTgenerated currents in Xenopus oocytes. Representative electrophysiological traces for 4-MEC (a) and 4-MePPP (b). Concentration-response curves, pooled from different oocytes for 4-MEC and 4-MePPP (c). Data in (c) are mean \pm SEM for $n=8$ oocytes from two independent preparations. Maximal current for 4-MEC was measured at $30 \mu \mathrm{M}$ and no current was observed for 4-MePPP.

Table I Residues Surrounding the Cationic Nitrogen of Cathinone-Type Ligands in Human SERT and DAT

\begin{tabular}{lllllll}
\hline SERT & Y95 & A96 & D98 & F335 & S336 & G338 \\
DAT & F76 & A77 & D79 & F320 & S321 & G323 \\
\hline
\end{tabular}

Abbreviations: A, alanine; D, aspartate; F, phenylalanine; G, glycine; S, serine: Y, tyrosine.

activity at SERT and blocker activity at DAT, a profile that we call 'hybrid' transporter activity. Simmler et al (2014) reported data consistent with our findings, showing 4-MEC is a 5 -HT releaser but a blocker at hDAT and hNET. Although this profile is unusual, it has been reported previously (Blough et al, 2014; Simmler et al, 2014; Yu et al,
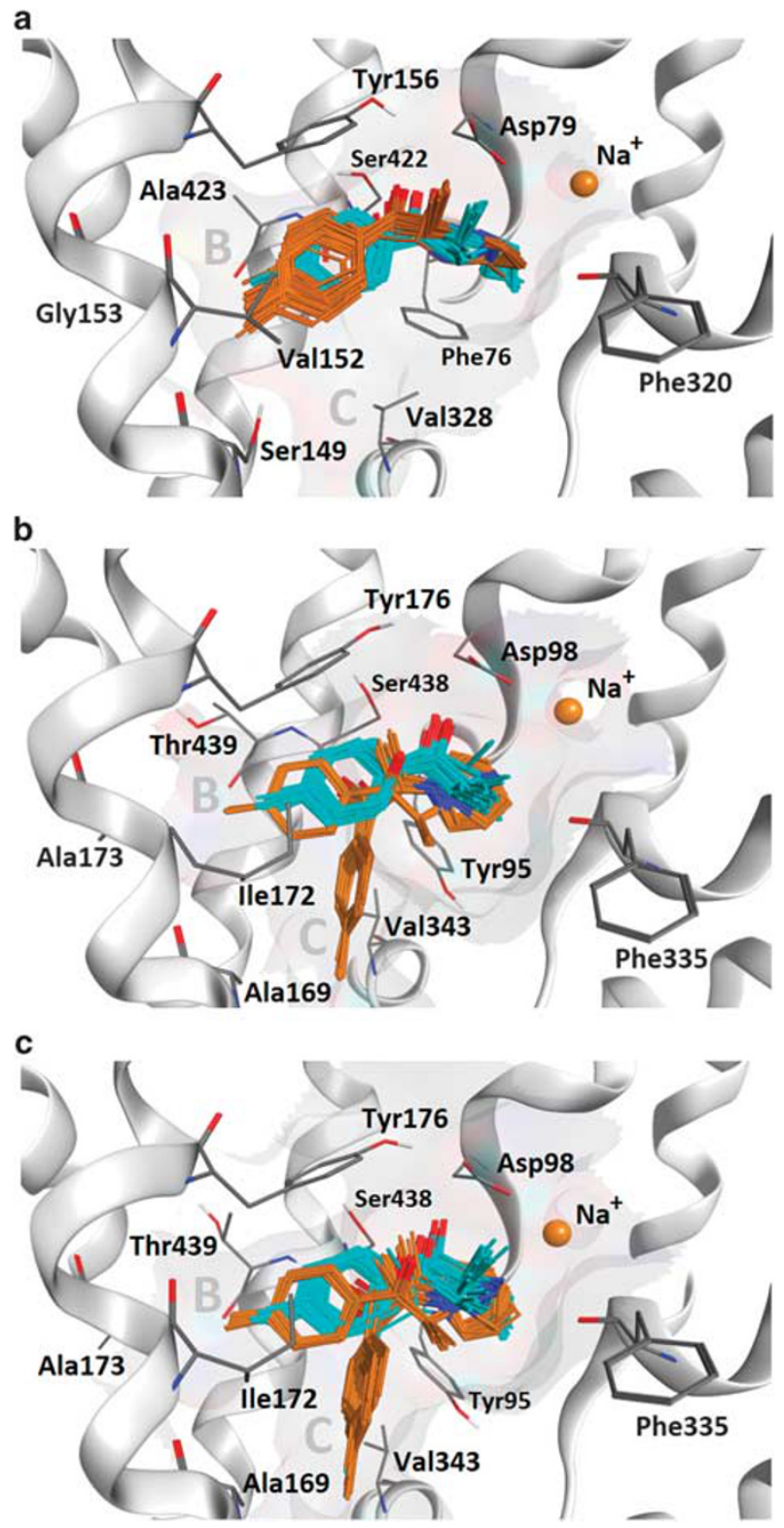

Figure 6 Central binding site of (a) DAT with docking poses of 4-MEC (cyan) and 4-MePPP (orange), (b) SERT with the Thr439 hydroxyl pointing toward the SI site, and (c) SERT with the Thr439 methyl pointing toward the SI site. The poses of both ligands in DAT are very consistent whereby the 4-methyl group points into subsite B. The same consistency is found in SERT for 4-MEC, but not for 4-MePPP, presumably because of an unfavorable fit into this subpocket forced by the larger substituent on the nitrogen atom.

2000). Yu et al (2000) described SERT substrate/ DAT blocker activity for $N$-ethylaminopropiophenone (ie, $\mathrm{N}$-ethylcathinone), a bioactive metabolite of the clinically available appetite suppressant diethylpropion. 4-MEC and $\mathrm{N}$-ethylcathinone display similar chemical structures, and hence it appears that extension of the $\mathrm{N}$-alkyl chain of cathinone compounds, from $\mathrm{N}$-methyl to $\mathrm{N}$-ethyl, is sufficient to convert activity at DAT from a substrate (eg, mephedrone) to a blocker (eg, 4-MEC). In contrast, mephedrone and 4-MEC display nearly equivalent effects 
as 5-HT releasers, suggesting that minor changes in $\mathrm{N}$-alkyl chain length do not alter substrate activity at SERT. The data with 4 -MEC and $N$-ethylcathinone illustrate the close structural resemblance among synthetic cathinones in the 'street drug' marketplace and those being prescribed clinically, such as diethylpropion and bupropion (Carroll et al, 2014; Cercato et al, 2009). Indeed, Blough et al (2014) have proposed that hybrid transporter compounds based on the $N$-cyclopropylcathinone structure could have value in the treatment of substance use disorders. Future studies should be carried out to examine the possible therapeutic potential of hybrid transporter ligands.

Extending the $\mathrm{N}$-alkyl chain of 4-MEC to form the pyrrolidine ring structure of 4-MePPP has marked effects on pharmacology, converting the compound to a DATselective transporter blocker. In fact, the in vitro pharmacology of 4-MePPP resembles that of pyrrolidinophenone compounds like pyrovalerone and MDPV rather than mephedrone (Baumann et al, 2013b; Cameron et al, 2013; Kolanos et al, 2013; Marusich et al, 2014). Meltzer et al (2006) reported that pyrovalerone analogs are potent blockers at DAT and NET with little influence on SERT. More recently, we demonstrated that MDPV, $\alpha$-PVP, and related pyrrolidinophenones are potent and selective blockers at DAT and NET in rat brain synaptosomes (Baumann et al, 2013b; Marusich et al, 2014). Kolanos et al (2013) examined the effects of MDPV and $\alpha$-PVP in Xenopus oocytes expressing hDAT and found that these compounds do not induce inward DAT-mediated currents, consistent with the present results showing that 4-MePPP does not display DAT substrate activity. Collectively, the in vitro data indicate that cathinone analogs that possess a pyrrolidine ring structure, or perhaps other bulky $\mathrm{N}$-alkyl substituents, will function as selective uptake blockers at DAT and NET.

The present microdialysis results show that transporter activity of 4-MEC and 4-MePPP strongly influences the in vivo neurochemical and behavioral effects of the drugs. Administration of 4-MEC to rats produces predominant increases in extracellular 5-HT with small increases in extracellular dopamine, consistent with its hybrid transporter actions. The in vivo neurochemical profile of 4-MEC mimics the effects of mephedrone and methylone (Baumann et al, 2012; Kehr et al, 2011; Wright et al, 2012), but 4-MEC is less potent and has weaker effects on dopamine when compared with other ring-substituted cathinones. Previous studies have shown that 5-HT-releasing actions of amphetamines and cathinones can dampen dopamine-mediated locomotor and reinforcing effects in rats (Baumann et al, 2011; Bonano et al, 2014), and hence it might be predicted that 4-MEC has weak stimulant properties. In contrast, 4-MePPP produces selective increases in extracellular dopamine and robust locomotor activation. The in vivo neurochemical profile of 4-MePPP mimics the effects of MDPV (Baumann et al, 2013b), but 4-MePPP is 10 -fold less potent and its effects are short-lived. It is well established that elevations in extracellular dopamine in the nucleus accumbens are correlated with the magnitude of locomotor activation produced by stimulant drugs (Baumann et al, 2011; Zolkowska et al, 2009), and the hyperactivity produced by 4 -MePPP agrees with the reported locomotor effects of MDPV and related pyrrolidi- nophenones (Aarde et al, 2013b; Fantegrossi et al, 2013; Gatch et al, 2013; Marusich et al, 2014; Marusich et al, 2012). The selective increase in extracellular dopamine produced by 4-MePPP suggests that this drug will be readily self-administered (Aarde et al, 2013b; Watterson et al, 2014).

Our experiments in synaptosomes provide the advantage of rapid drug screening in native tissue, whereas experiments in cells allow a more detailed assessment of drugtransporter interactions. Here we examined the effects of 4-MEC and 4-MePPP in cells expressing hDAT and hSERT. In uptake inhibition assays, 4-MEC acts as a nonselective transporter blocker whereas 4-MePPP is selective for hDAT, in agreement with the findings in synaptosomes. It is noteworthy that $\mathrm{IC}_{50}$ values for 4 -MEC and 4-MePPP in transporter-expressing cells are somewhat higher (ie, apparent lower potency) than those determined in synaptosomes. Differences in assay procedures used for synaptosomes $v s$ cells could explain these differences. In addition, the complement of accessory membrane proteins present in synaptosomes may not be present in nonneuronal cell systems (Wilhelm et al, 2014), and this could influence absolute potency values. In the superfusion assays, 4-MEC evokes 5-HT efflux whereas 4-MePPP does not. The 5-HT efflux produced by $4-\mathrm{MEC}$ is markedly potentiated by monensin, an ionophore that dissipates $\mathrm{Na}+$ gradients across cell membranes enhancing intracellular $\mathrm{Na}+$ (Hofmaier et al, 2014). We have shown previously that monensin augments transporter-mediated efflux caused by substrates but not blockers (Baumann et al, 2013b; Hofmaier et al, 2014; Scholze et al, 2000), and hence the findings with monensin reported here provide decisive evidence that 4-MEC is a SERT substrate. 4-MEC and 4MePPP also evoke modest efflux from hDAT, but these effects are not altered by monensin, confirming that neither drug is a DAT substrate. Our data from cells expressing human transporters reinforce the findings from rat brain tissue, and serve to validate the translational value of studying cathinone-type drugs in rodent models.

Perhaps the most sophisticated method for examining the interactions of drugs with monoamine transporters involves the measurement of transporter-mediated ionic currents (Sitte et al, 1998; Sonders et al, 1997). Because the SLC6 transporters co-transport $\mathrm{Na}+$ ions along with substrate, inward depolarizing current is generated during translocation of substrate from the outside of the cell to the inside (Kristensen et al, 2011). Thus, measuring the electrophysiological signature of transporter ligands can give direct information about the molecular mechanism of action for these substances. We found that 4-MEC, but not 4-MePPP, induces inward current analogous to prototypical SERT substrates like fenfluramine and $p$-chloroamphetamine (Baumann et al, 2014; Gobbi et al, 2008). Moreover, the current dose-response relationship with 4-MEC appears bell shaped, similar to the effects of other transporter substrates. The decrease in current measured at the highest concentration of 4 -MEC (ie, $100 \mu \mathrm{M}$ ) is likely because of the intracellular accumulation of substrate that tends to inhibit SERT-mediated current (Adams and DeFelice, 2003). We have previously shown that the magnitude of inward current produced by SERT substrates may be involved in the persistent 5-HT depletions caused by these drugs in rats 
(Baumann et al, 2014; Gobbi et al, 2008). Our electrophysiological findings with 4-MEC suggest that future studies should examine the potential for this drug to produce long-term serotonergic deficits in rodent models.

Based on the present structure-activity data, a crucial question arises: how does extending the $N$-alkyl chain of mephedrone produce major changes in pharmacology? We carried out molecular modeling studies to address this question, with specific reference to the structural differences between 4-MEC ( $N$-ethyl) and 4-MePPP ( $N$-containing pyrrolidine ring) that lead to marked loss of activity at SERT for 4-MePPP. Using a computational docking approach based on $\mathrm{dDAT}_{\text {cryst }}$ (Penmatsa et al, 2013), we show that the binding subpocket $B$ of SERT is smaller because of bulkier amino-acid side chains when compared with the binding subpocket of DAT. Therefore, it is tempting to speculate that SERT is less able to accommodate the bulky pyrrolidine ring structure of 4-MePPP when compared with the smaller $N$-ethyl chain of 4 -MEC. The present modeling approach may have key predictive value when attempting to understand transporter selectivity of new cathinone analogs as they appear in the recreational drug marketplace.

To summarize, the structure-activity data reported here demonstrate that changing the $N$-alkyl substituent of cathinone drugs can profoundly influence their pharmacology. 4-MEC is a SERT substrate/DAT blocker with predominant 5-HT-releasing effects in vivo. The serotonergic actions of 4-MEC may reduce its stimulant properties but enhance its propensity for producing long-term 5-HT deficits. 4-MePPP is a selective DAT blocker with robust locomotor stimulant effects in vivo. Although our study focused on the effects of drugs on DAT and SERT, it seems likely that 4-MEC and 4-MePPP interact with NET as well (eg, see Simmler et al, 2014). Future studies should examine the neurotoxic potential, abuse liability, and noradrenergic actions of 4-MEC, 4-MePPP, and other newly emerging cathinone derivatives.

\section{FUNDING AND DISCLOSURE}

HHS has received honoraria for lectures and consulting from Lundbeck, Ratiopharm, Roche, Sanofi-Aventis, and Serumwerk Bernburg. The other authors declare no conflict of interest.

\section{ACKNOWLEDGEMENTS}

This research was supported by the Austrian Research Fund/FWF grants F3506 and W1232 to HHS and the Intramural Research Program of the NIDA, NIH, grant DA000523-07 to MHB.

\section{REFERENCES}

Aarde SM, Angrish D, Barlow DJ, Wright MJ Jr, Vandewater SA, Creehan KM et al (2013a). Mephedrone (4-methylmethcathinone) supports intravenous self-administration in SpragueDawley and Wistar rats. Addict Biol 18: 786-799.

Aarde SM, Huang PK, Creehan KM, Dickerson TJ, Taffe MA (2013b). The novel recreational drug 3,4-methylenedioxypyrovalerone (MDPV) is a potent psychomotor stimulant: self-administration and locomotor activity in rats. Neuropharmacology 71: 130-140.

Adams SV, DeFelice LJ (2003). Ionic currents in the human serotonin transporter reveal inconsistencies in the alternating access hypothesis. Biophys J 85: 1548-1559.

Andersen J, Olsen L, Hansen KB, Taboureau O, Jorgensen FS, Jorgensen AM et al (2010). Mutational mapping and modeling of the binding site for (S)-citalopram in the human serotonin transporter. J Biol Chem 285: 2051-2063.

Ayres TC, Bond JW (2012). A chemical analysis examining the pharmacology of novel psychoactive substances freely available over the internet and their impact on public (ill)health. Legal highs or illegal highs? BMJ Open 2: e000977.

Baumann MH, Ayestas MA Jr, Partilla JS, Sink JR, Shulgin AT, Daley PF et al (2012). The designer methcathinone analogs, mephedrone and methylone, are substrates for monoamine transporters in brain tissue. Neuropsychopharmacology 37: 1192-1203.

Baumann MH, Bulling S, Benaderet TS, Saha K, Ayestas MA, Partilla JS et al (2014). Evidence for a role of transportermediated currents in the depletion of brain serotonin induced by serotonin transporter substrates. Neuropsychopharmacology 39: $1355-1365$.

Baumann MH, Clark RD, Woolverton WL, Wee S, Blough BE, Rothman RB (2011). In vivo effects of amphetamine analogs reveal evidence for serotonergic inhibition of mesolimbic dopamine transmission in the rat. J Pharmacol Exp Ther 337: 218-225.

Baumann MH, Partilla JS, Lehner KR (2013a). Psychoactive "bath salts": not so soothing. Eur J Pharmacol 698: 1-5.

Baumann MH, Partilla JS, Lehner KR, Thorndike EB, Hoffman AF, Holy $M$ et al (2013b). Powerful cocaine-like actions of 3,4-methylenedioxypyrovalerone (MDPV), a principal constituent of psychoactive 'bath salts' products. Neuropsychopharmacology 38: 552-562.

Blough BE, Landavazo A, Partilla JS, Baumann MH, Decker AM, Page KM et al (2014). Hybrid dopamine uptake blockerserotonin releaser ligands: a new twist on transporter-focused therapeutics. ACS Med Chem Lett 5: 623-627.

Bonano JS, Glennon RA, De Felice LJ, Banks ML, Negus SS (2014). Abuse-related and abuse-limiting effects of methcathinone and the synthetic "bath salts" cathinone analogs methylenedioxypyrovalerone (MDPV), methylone and mephedrone on intracranial self-stimulation in rats. Psychopharmacology 231: 199-207.

Brandt SD, Freeman S, Sumnall HR, Measham F, Cole J (2011). Analysis of NRG 'legal highs' in the UK: identification and formation of novel cathinones. Drug Test Anal 3: 569-575.

Cameron KN, Kolanos R, Solis E Jr, Glennon RA, De Felice LJ (2013). Bath salts components mephedrone and methylenedioxypyrovalerone (MDPV) act synergistically at the human dopamine transporter. $\mathrm{Br}$ J Pharmacol 168: 1750-1757.

Carroll FI, Blough BE, Mascarella SW, Navarro HA, Lukas RJ, Damaj MI (2014). Bupropion and bupropion analogs as treatments for CNS disorders. Adv Pharmacol 69: 177-216.

Cercato C, Roizenblatt VA, Leanca CC, Segal A, Lopes Filho AP, Mancini MC et al (2009). A randomized double-blind placebocontrolled study of the long-term efficacy and safety of diethylpropion in the treatment of obese subjects. Int $J$ Obes 33: $857-865$

Dargan PI, Sedefov R, Gallegos A, Wood DM (2011). The pharmacology and toxicology of the synthetic cathinone mephedrone (4-methylmethcathinone). Drug Test Anal 3: 454-463.

De Felice LJ, Glennon RA, Negus SS (2014). Synthetic cathinones: chemical phylogeny, physiology, and neuropharmacology. Life Sci 97: 20-26.

Drug Enforcement Administration (DEA), Department of Justice (2013). Establishment of drug codes for 26 substances. Final rule. Fed Regist 78: 664-666. 
Eshleman AJ, Wolfrum KM, Hatfield MG, Johnson RA, Murphy KV, Janowsky A (2013). Substituted methcathinones differ in transporter and receptor interactions. Biochem Pharmacol 85: 1803-1815.

Fantegrossi WE, Gannon BM, Zimmerman SM, Rice KC (2013). In vivo effects of abused 'bath salt' constituent 3,4-methylenedioxypyrovalerone (MDPV) in mice: drug discrimination, thermoregulation, and locomotor activity. Neuropsychopharmacology 38: $563-573$.

Gatch MB, Taylor CM, Forster MJ (2013). Locomotor stimulant and discriminative stimulus effects of 'bath salt' cathinones. Behav Pharmacol 24: 437-447.

Gil D, Adamowicz P, Skulska A, Tokarczyk B, Stanaszek R (2013). Analysis of 4-MEC in biological and non-biological materialthree case reports. Forensic Sci Int 228: e11-e15.

Gobbi M, Funicello M, Gerstbrein K, Holy M, Moya PR, Sotomayor $\mathrm{R}$ et al (2008). N,N-dimethyl-thioamphetamine and methylthioamphetamine, two non-neurotoxic substrates of 5-HT transporters, have scant in vitro efficacy for the induction of transporter-mediated 5-HT release and currents. J Neurochem 105: $1770-1780$

Hadlock GC, Webb KM, McFadden LM, Chu PW, Ellis JD, Allen SC et al (2011). 4-Methylmethcathinone (mephedrone): neuropharmacological effects of a designer stimulant of abuse. J Pharmacol Exp Ther 339: 530-536.

Hofmaier T, Luf A, Seddik A, Stockner T, Holy M, Freissmuth M et al (2014). Aminorex, a metabolite of the cocaine adulterant levamisole, exerts amphetamine like actions at monoamine transporters. Neurochem Int 73: 32-41.

Hou T, Wang J, Li Y, Wang W (2011). Assessing the performance of the MM/PBSA and MM/GBSA methods. 1. The accuracy of binding free energy calculations based on molecular dynamics simulations. J Chem Inf Model 51: 69-82.

Jones G, Willett P, Glen RC, Leach AR, Taylor R (1997). Development and validation of a genetic algorithm for flexible docking. J Mol Biol 267: 727-748.

Jorgensen WL, Maxwell DS, Tirado Rives J (1996). Development and testing of the OPLS all-atom force field on conformational energetics and properties of organic liquids. J Am Chem Soc 118: 11225-11236.

Kehr J, Ichinose F, Yoshitake S, Goiny M, Sievertsson T, Nyberg F et al (2011). Mephedrone, compared with MDMA (ecstasy) and amphetamine, rapidly increases both dopamine and 5-HT levels in nucleus accumbens of awake rats. Br J Pharmacol 164: 1949-1958.

Kolanos R, Solis E Jr, Sakloth F, De Felice LJ, Glennon RA (2013). "Deconstruction" of the abused synthetic cathinone methylenedioxypyrovalerone (MDPV) and an examination of effects at the human dopamine transporter. ACS Chem Neurosci 4: 1524-1529.

Kristensen AS, Andersen J, Jorgensen TN, Sorensen L, Eriksen J, Loland CJ et al (2011). SLC6 neurotransmitter transporters: structure, function, and regulation. Pharmacol Rev 63: 585-640.

Leffler AM, Smith PB, de Armas A, Dorman FL (2014). The analytical investigation of synthetic street drugs containing cathinone analogs. Forensic Sci Int 234: 50-56.

Lewin AH, Seltzman HH, Carroll FI, Mascarella SW, Reddy PA (2014). Emergence and properties of spice and bath salts: a medicinal chemistry perspective. Life Sci 97: 9-19.

Lopez-Arnau R, Martinez-Clemente J, Pubill D, Escubedo E, Camarasa J (2012). Comparative neuropharmacology of three psychostimulant cathinone derivatives: butylone, mephedrone and methylone. Br J Pharmacol 167: 407-420.

Marinetti LJ, Antonides HM (2013). Analysis of synthetic cathinones commonly found in bath salts in human performance and postmortem toxicology: method development, drug distribution and interpretation of results. J Anal Toxicol 37: 135-146.
Marusich JA, Antonazzo KR, Wiley JL, Blough BE, Partilla JS, Baumann MH (2014). Pharmacology of novel synthetic stimulants structurally related to the "bath salts" constituent 3,4-methylenedioxypyrovalerone (MDPV). Neuropharmacology 87: 206-213.

Marusich JA, Grant KR, Blough BE, Wiley JL (2012). Effects of synthetic cathinones contained in "bath salts" on motor behavior and a functional observational battery in mice. Neurotoxicology 33: 1305-1313.

Meltzer PC, Butler D, Deschamps JR, Madras BK (2006). 1-(4Methylphenyl)-2-pyrrolidin-1-yl-pentan-1-one (Pyrovalerone) analogues: a promising class of monoamine uptake inhibitors. J Med Chem 49: 1420-1432.

Penmatsa A, Wang KH, Gouaux E (2013). X-ray structure of dopamine transporter elucidates antidepressant mechanism. Nature 503: 85-90.

Rojek S, Klys M, Maciow-Glab M, Kula K, Strona M (2014). Cathinones derivatives-related deaths as exemplified by two fatal cases involving methcathinone with 4-methylmethcathinone and 4-methylethcathinone. Drug Test Anal 6: 770-777.

Rosenbaum CD, Carreiro SP, Babu KM (2012). Here today, gone tomorrow...and back again? A review of herbal marijuana alternatives (K2, Spice), synthetic cathinones (bath salts), kratom, Salvia divinorum, methoxetamine, and piperazines. J Med Toxicol 8: 15-32.

Rothman RB, Baumann MH (2003). Monoamine transporters and psychostimulant drugs. Eur J Pharmacol 479: 23-40.

Sali A, Potterton L, Yuan F, van Vlijmen H, Karplus M (1995). Evaluation of comparative protein modeling by MODELLER. Proteins 23: $318-326$.

Scholze P, Zwach J, Kattinger A, Pifl C, Singer EA, Sitte HH (2000). Transporter-mediated release: a superfusion study on human embryonic kidney cells stably expressing the human serotonin transporter. J Pharmacol Exp Ther 293: 870-878.

Seddik A, Holy M, Weissensteiner R, Zdrazil B, Sitte HH, Ecker GF (2013). Probing the selectivity of monoamine transporter substrates by means of molecular modeling. Mol Inform 32: 409-413.

Simmler LD, Buser TA, Donzelli M, Schramm Y, Dieu LH, Huwyler J et al (2013). Pharmacological characterization of designer cathinones in vitro. Br J Pharmacol 168: 458-470.

Simmler LD, Rickli A, Hoener MC, Liechti ME (2014). Monoamine transporter and receptor interaction profiles of a new series of designer cathinones. Neuropharmacology 79: 152-160.

Sitte HH, Freissmuth M (2010). The reverse operation of $\mathrm{Na}(+) /$ $\mathrm{Cl}(-)$-coupled neurotransmitter transporters-why amphetamines take two to tango. J Neurochem 112: 340-355.

Sitte HH, Huck S, Reither H, Boehm S, Singer EA, Pifl C (1998). Carrier-mediated release, transport rates, and charge transfer induced by amphetamine, tyramine, and dopamine in mammalian cells transfected with the human dopamine transporter. J Neurochem 71: 1289-1297.

Sonders MS, Zhu SJ, Zahniser NR, Kavanaugh MP, Amara SG (1997). Multiple ionic conductances of the human dopamine transporter: the actions of dopamine and psychostimulants. J Neurosci 17: 960-974.

Spiller HA, Ryan ML, Weston RG, Jansen J (2011). Clinical experience with and analytical confirmation of "bath salts" and "legal highs" (synthetic cathinones) in the United States. Clin Toxicol 49: 499-505.

Springer D, Fritschi G, Maurer HH (2003). Metabolism of the new designer drug alpha-pyrrolidinopropiophenone (PPP) and the toxicological detection of PPP and $4^{\prime}$-methyl-alpha-pyrrolidinopropiophenone (MPPP) studied in rat urine using gas chromatography-mass spectrometry. J Chromatogr B Analyt Technol Biomed Life Sci 796: 253-266.

Springer D, Peters FT, Fritschi G, Maurer HH (2002). Studies on the metabolism and toxicological detection of the new designer 
drug $4^{\prime}$-methyl-alpha-pyrrolidinopropiophenone in urine using gas chromatography-mass spectrometry. J Chromatogr B Analyt Technol Biomed Life Sci 773: 25-33.

Steinkellner T, Freissmuth M, Sitte HH, Montgomery T (2011). The ugly side of amphetamines: short- and long-term toxicity of 3,4methylenedioxymethamphetamine (MDMA, 'Ecstasy'), methamphetamine and D-amphetamine. Biol Chem 392: 103-115.

Tatsumi M, Groshan K, Blakely RD, Richelson E (1997). Pharmacological profile of antidepressants and related compounds at human monoamine transporters. Eur J Pharmacol 340: 249-258.

Thompson JD, Gibson TJ, Higgins DG (2002). Multiple sequence alignment using ClustalW and ClustalX. Curr Protoc Bioinformatics Chapter 2: Unit 2.3.

Wang H, Goehring A, Wang KH, Penmatsa A, Ressler R, Gouaux E (2013). Structural basis for action by diverse antidepressants on biogenic amine transporters. Nature 503: 141-145.

Watterson LR, Kufahl PR, Nemirovsky NE, Sewalia K, Grabenauer $\mathrm{M}$, Thomas BF et al (2014). Potent rewarding and reinforcing effects of the synthetic cathinone 3,4-methylenedioxypyrovalerone (MDPV). Addict Biol 19: 165-174.

Wilhelm BG, Mandad S, Truckenbrodt S, Krohnert K, Schafer C, Rammner B et al (2014). Composition of isolated synaptic boutons reveals the amounts of vesicle trafficking proteins. Science 344: 1023-1028.

Wright MJ Jr, Angrish D, Aarde SM, Barlow DJ, Buczynski MW, Creehan KM et al (2012). Effect of ambient temperature on the thermoregulatory and locomotor stimulant effects of 4-methylmethcathinone in Wistar and Sprague-Dawley rats. PLoS One 7: e44652.

Yu H, Rothman RB, Dersch CM, Partilla JS, Rice KC (2000). Uptake and release effects of diethylpropion and its metabolites with biogenic amine transporters. Bioorg Med Chem 8: 2689-2692.

Zolkowska D, Jain R, Rothman RB, Partilla JS, Roth BL, Setola V et al (2009). Evidence for the involvement of dopamine transporters in behavioral stimulant effects of modafinil. J Pharmacol Exp Ther 329: 738-746. 